\title{
Diagnósticos organizacionais: a contribuição da pesquisa em relações públicas
}

\author{
Organizational diagnostics: the contribution \\ of public relations research
}

Diagnósticos organizacionales: la contribución de la investigación de las relaciones públicas

Valéria de Siqueira Castro Lopes

- Doutora e mestre em Ciências da Comunicação pela Escola de Comunicações e Artes da Universidade de São Paulo (ECA-USP)

- $\quad$ Graduada em Relações Públicas pela Universidade do Estado do Rio de Janeiro (Uerj)

- Docente nos cursos de Relações Públicas da ECA-USP e da Faculdade Cásper Líbero (Facásper)

- Professora do Curso de Especialização em Gestão Estratégica de Comunicação Organizacional e Relações Públicas da ECA-USP (Gestcorp/ECA-USP)

- Membro do Conselho Fiscal da Associação Brasileira de Pesquisadores de Comunicação Organizacional e de Relações Públicas (Abrapcorp)

- E-mail:vsclopes@uol.com.br

\section{Vânia Penafieri}

- Doutora e mestre em Comunicação e Semiótica pela Pontifícia Universidade Católica de São Paulo (PUC-SP)

- Especialista em Comunicação e Marketing pela Faculdade Cásper Líbero (Facásper)

- Bacharel em Relações Públicas pela Facásper

- Professora nos cursos de Relações Públicas da Facásper e do Centro Universitário Belas Artes

- Integra o corpo docente do Curso de Publicidade e Propaganda da PUC-SP

- Diretora científica da Associação Brasileira de Pesquisadores de Comunicação Organizacional e de Relações Públicas (gestão 2016-2018)

- E-mail: vpenafieri@gmail.com 


\section{Resumo}

0 presente artigo propõe mecanismos de construção de diagnósticos a partir de modelos de gestão alicerçados na administração e incorporados em cenários de comunicação. Os modelos Toyota, BSC, de investigação apreciativa e de mudança organizacional são abordados no sentido de traduzirem aspectos relevantes e caminhos assertivos para construção de diagnósticos estratégicos. 0 estudo é finalizado com conceitos relacionados às pesquisas em comunicação, que se projetam como elementos prévios de concepção de diagnósticos e contribuem para elucidar itens incorporados nos modelos apresentados.

\section{PALAVRAS-CHAVE: ESTRATÉGIA•RDIAGNÓSTICOS ORGANIZACIONAIS•MODELOS DE GESTÃO.}

\section{Abstract}

This article proposes diagnosis building mechanisms based on business management models and incorporated into communication scenarios. The Toyota, balanced scorecard (BSC), appreciative inquiry and organizational change models are addressed to translate relevant aspects and assertive paths to building strategic diagnostics. The study concludes with concepts related to communication research which are projected as previous elements for diagnosis and contribute to elucidate items that are present in these models.

\section{KEYWORDS: STRATEGY • ORGANIZATIONAL DIAGNOSIS • MANAGEMENT MODELS.}

\section{Resumen}

Este artículo propone mecanismos de construcción de diagnósticos a partir de modelos de gestión fundamentados en la administración e incorporados en escenarios de comunicación. Los modelos Toyota, balanced scorecard (BSC), de investigación apreciativa y de cambio organizacional son abordados para traducir los aspectos relevantes y los caminos asertivos para construir diagnósticos estratégicos. El estudio finaliza con conceptos relacionados a la investigación en comunicación, proyectados como elementos anteriores de concepción de diagnósticos y que contribuyen para dilucidar los elementos integrados a los modelos presentados. 
pesquisa é etapa essencial na condução das atividades de relações públicas, especialmente em cenários onde ela transita $\triangle$ da função operacional para a gerencial, uma vez que a tomada de decisão deve ser balizada por dados precisos. Éa pesquisa estratégica, ou seja, aquela voltada à formulação de diagnóstico e elaboração do plano de ação que estabelece foco e direção ao planejamento de relações públicas, uma vez que auxilia na identificação de cenários organizacionais e problemas de comunicação - falhas na comunicação e/ou na gestão de relacionamentos entre uma organização e seus públicos.

0 processo de planejamento inicia-se com levantamento de dados secundários que permitirão ao profissional conhecer a organização e seu cenário do entorno, para que seja possível a construção do diagnóstico de relações públicas. Dessa forma, serão apresentados o conceito de diagnóstico, suas principais características, alguns modelos de negócio como abordagem para sua construção tanto no âmbito organizacional quanto no comunicacional. Em seguida, serão discutidos os usos da pesquisa na elaboração do diagnóstico em relações públicas.

\section{ELEMENTOS PARA CONSTRUÇÃO DE DIAGNÓSTICOS ESTRATÉGICOS}

\section{Diagnóstico organizacional: definição e características}

0 diagnóstico pode ser definido como processo de avaliação da realidade organizacional, realizado com o propósito de manter e ampliar as competências da organização, além de auxiliar na tomada de decisão. De acordo com Tavares (2000, p. 268), o diagnóstico pode ser categorizado como estratégico, o qual abarca toda a organização, com o intuito de obter uma visão abrangente do cenário organizacional, ou técnico, cujo foco é uma de suas áreas, funções ou processos, visando a seu detalhamento e sua compreensão.

0 processo de elaboração do diagnóstico estratégico inicia-se pela confrontação das atividades e dos processos desenvolvidos pela organização que vão ao encontro do cumprimento de sua missão e de uma melhor visão de futuro. Em seguida, determina-se o gap entre o que a organização é e o que pretende ser, indicando-se as mudanças processuais necessárias à consecução de seus objetivos, bem como um processo de avaliação das propostas em relação a tempo, custos e recursos consumidos (TAVARES, 2000).

A seção seguinte tratará da construção do diagnóstico organizacional, em seu âmbito estratégico, a partir da formulação e dos modelos de gestão da estratégia.

\section{Abordagens para a construção do diagnóstico organizacional}

\section{Conceitos de estratégia}

Compreender a abrangência da estratégia e como ela passa a ser incorporada nos processos de gestão organizacional contribui para uma visão mais ampla de assuntos que possam ser tratados estrategicamente em pesquisas primárias ou secundárias e, em um segundo momento, para a construção de diagnósticos mais assertivos.

Eliezer Costa (2007) cita o fornecimento de produtos ou serviços de ponta, a busca da excelência operacional e o estreitamento do relacionamento da organização com seus clientes como as principais opções estratégicas, que, certamente, possibilitariam 
um processo de gestão mais fortemente direcionado. No entanto, o autor enfatiza ser imprescindível para as organizações a definição de uma única opção, o que de fato possa ser entendido como vantagem competitiva e direcionamento da organização para o futuro, tendo em vista que as demais opções possam ser trabalhadas como coadjuvantes do processo de gestão.

Para que aspectos estratégicos possam ser incorporados aos diagnósticos organizacionais, é importante ressaltar o exposto por Costa (2007, p. 40) como 'triângulo estratégico', em que o autor considera três pontos fundamentais: o propósito da organização (o que nós queremos ser?), o ambiente externo (o que nos é permitido fazer?) e a capacitação (o que nós sabemos fazer?). Com a identificação e análise dos três pontos elencados surgem as estratégias (o que nós vamos fazer?), preenchendo e dando sentido à relação triádica concebida preliminarmente, conforme Figura 1.

Figura 1-Bases para a formulação da estratégia.

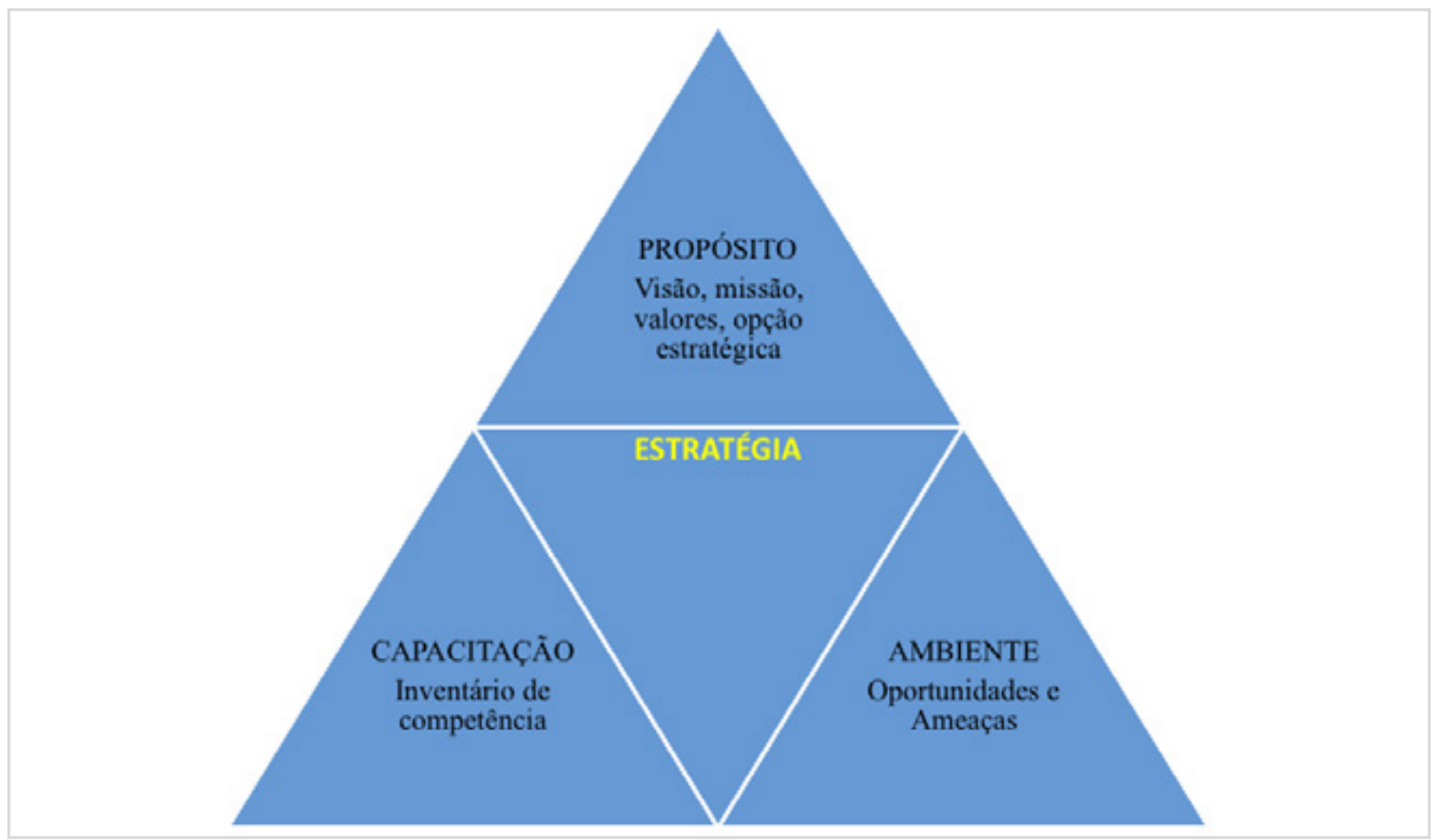

Fonte: Costa (2007, p. 40).

\section{Sistema Toyota de produção}

O sistema Toyota de produção, também conhecido como modelo Toyota, é base do movimento de "produção enxuta" juntamente com o "seis sigma". O modelo, de acordo com Jefrey Liker e David Meier (2007), pressupõe que o conceito de empresa enxuta deva permear toda a organização, o que significa definir o valor do cliente a partir de sua demanda (just in time), buscando a excelência por meio da melhoria contínua.

De acordo com a metodologia, a melhoria contínua deve ser responsabilidade de todos os membros da organização, incluindo a alta gestão, que, de acordo com os preceitos do modelo, deve estar envolvida com operações da organização. Nesse ponto, observa-se que o modelo Toyota, assim como outros modelos de gestão abordados neste artigo, critica o hiato existente entre planejamento e sua implantação, causa do distanciamento entre consultores, planejadores e executores do plano de negócio, presente na década de 1980. Em resposta a esse distanciamento entre gestão e operação, surgem na década seguinte, assim como o ciclo PDCA, metodologias que propõem aproximar planejamento e administração estratégica em busca da incorporação de mudanças rápidas que proporcionem à organização flexibilidade, inovação e criatividade. 
Metodologia PDCA

A metodologia PDCA (plan, do, check, act) é um ciclo de planejamento, execução, avaliação e correção que busca identificar problemase solucioná-los em oitoetapas:identificação do problema; descrição do problema; estudodo problema; desenvolvimento das soluções; discussão das soluções com todos os membros da equipe; aprovação; implementação; e avaliação.

Em função do escopo do presente artigo, cabe apenas a análise e discussão da primeira etapa do ciclo - plan-, dedicada ao diagnóstico organizacional. Essa etapa do ciclo é iniciada pela identificação e descrição (clara, concisa e mensurável) do problema, aqui reconhecido como um desvio em relação a uma norma (standard). Em seguida, a metodologia propõe a análise do contexto onde se verifica o problema por meio dos questionamentos (5W2H): 0 que é o problema? Onde 0 problema ocorre? Quando ele ocorre? Quem está envolvido ou é afetado pelo problema? Como se dá o problema? Quanto ele custa? 0 terceiro passo do plan refere-se à identificação das causas do problema e, para tanto, sugere que o gestor busque identificá-las questionando-se $(5 \mathrm{~W} 1 \mathrm{H})$ : 0 que é causa provável do problema? Onde ela(s) está(ão)? Quando as causas ocorrem (sazonalidade)? Quem está envolvido ou é responsável pela causa do problema? Por que a causa do problema ocorre? Quanto ela custa?

\section{Balanced scorecard}

O balanced scorecard(BSC), criado pelos consultores Robert Kaplan e David Norton (2003), constitui um conjunto de medidas de desempenho que serve de base para uma gestão estratégica e resulta de suas críticas aos sistemas tradicionais de mensuração de desempenho, focados em medidas financeiras de curto prazo. Kaplan e Norton acreditam que tais medidas dificultam a criação de valor econômico para o futuro e, por isso, propõem no BSC o equilíbrio de medidas de curto e longo prazo, tangíveis e intangíveis, de âmbito interno e externo.

A falta de ligação entre estratégia e operação é mais uma crítica feita por Kaplan e Norton, que alçam o BSC de ferramenta de avaliação de desempenho financeiro, em um primeiro momento, a sistema de gestão estratégica, em sua fase mais recente. A adoção da ferramenta como sistema de gestão foi propiciada pela percepção de seus usuários de que a metodologia vincula plano estratégico e operacional por meio do uso de medidas de desempenho não-financeiras relacionadas à estratégia, proporcionando sua comunicação e seu alinhamento interno.

O sistema de gestão da estratégia é utilizado na busca pela excelência empresarial, pois permite ao gestor refletir sobre sua validade e viabilidade. A estratégia de negócio é traduzida em objetivos que direcionam seu comportamento e desempenho e são distribuídos em quatro perspectivas: finanças, clientes, processos internos, aprendizado e conhecimento. A conexão dos objetivos das quatro perspectivas em uma relação de causa e efeito resulta no mapa estratégico. 0 mapa deve traduzir o planejamento e ter por função definir o foco dos negócios, além de descrever o que é valor para uma determinada organização, como ele pode ser criado e mensurado.

A contribuição do modelo BSC para a construção de diagnósticos estratégicos é evidenciada por Araújo (2009, p. 83-84), ao aglutinar a visão de diferentes autores sobre o assunto. 0 autor apresenta as principais razões para seu uso, em que se destacam seis pontos: a vantagem competitiva é proporcionada por indicadores de desempenho, permitindo uma avaliação mais precisa do momento atual da organização e por projeções futuras; possibilita que esforços sejam direcionados para áreas de maior competência; fornece meios e modos para gozar das oportunidades que o ambiente externo oferece a partir 
de projeções no cotidiano da organização; permite a formulação de estratégias de forma mais ativa e dinâmica em função da inserção de variáveis observadas no ambiente; permite obter feedback para aprofundar o conhecimento das estratégias e aperfeiçoá-las, uma vez que o processo cíclico é evidenciado; e, por fim, possui o alinhamento dos objetivos pessoais, de áreas específicas da organização e da organização como um todo.

Entendendo que os benefícios do BSC estão relacionados a pessoas, atividades e controle de gestão, o autor destaca ainda que, "ao se utilizarem diversas perspectivas de forma integrada, a abordagem permite que se tenha uma visão de futuro, 0 que o diferencia dos demais sistemas de avaliação de desempenho" (ARAÚJ0, 2009, p. 85).

\section{Investigação apreciativa}

A investigação apreciativa é um modelo de gestão de mudanças, proposto pelo acadêmico David Cooperrider (2006), que possibilita o envolvimento dos funcionários, clientes e outros interessados no futuro da organização. Com foco nos pontos fortes do negócio e em suas vantagens estratégicas, o modelo apreciativo busca fugir da abordagem normalmente adotada no processo de gestão, focada em problemas, tal como explicita o Quadro 1.

O processo de implementação desse modelo busca descobrir o que anima uma organização em seus momentos de eficiência, fazendo perguntas capazes de fortalecer o seu potencial positivo, aqui denominado como núcleo positivo. Dessa forma, 0 ciclo apreciativo vincula o conhecimento e a energia do núcleo positivo de uma organização para a agenda de mudanças.

Quadro 1 - Diferenças conceituais e metodológicas

entre as escolas de planejamento tradicional e a investigação apreciativa.

\begin{tabular}{|l|l|}
\hline \multicolumn{1}{|c|}{ Solução de problemas } & \multicolumn{1}{c|}{ Investigação apreciativa } \\
\hline $\begin{array}{l}\text { Mudança = definição e busca } \\
\text { de solução de problema }\end{array}$ & Mudança = descoberta da organização \\
\hline $\begin{array}{l}\text { Solicita às pessoas que olhem } \\
\text { para o passado }\end{array}$ & Solicita a análise do núcleo positivo \\
\hline Raramente resulta em nova visão & Resulta na mudança positiva \\
\hline
\end{tabular}

Fonte: Adaptado de Cooperrider; Whitney, 2006.

0 ponto de partida do ciclo IA é denominado descoberta (discovery), quando toda a organização é mobilizada em busca de pontos fortes e melhores práticas. A metodologia propõe a adoção do diálogo e da aprendizagem em um processo de entrevistas para identificar o(s) tópico(s) afirmativo(s) que comporá(ão) o núcleo positivo, onde o conhecimento útil e inovador é compartilhado por e com todos os envolvidos. Pode-se afirmar que essa etapa equivale ao diagnóstico organizacional, referência para elaboração e realização da visão organizacional.

0 sonho (dream) constitui-se na visão construída a partir do potencial descoberto. As histórias e as impressões levantadas nas entrevistas são colocadas em uso como recurso para visualização do futuro coletivo. 0 planejamento (design)constrói uma proposta de organização ideal, onde os interessados se sintam capazes de tornar o sonho possível e ampliar o núcleo positivo. As pessoas são estimuladas a questionar o status organizacional, buscando a maximização 
das qualidades do núcleo positivo atual e realização acelerada do sonho. 0 destino (destiny) sustenta a iniciativa por mudança positiva contínua e alto desempenho em longo prazo, fortalecendo a capacidade positiva da organização e incentivando as pessoas a se libertarem dos fatos negativos.

Figura 2 - Ciclo 4-D da investigação apreciativa.

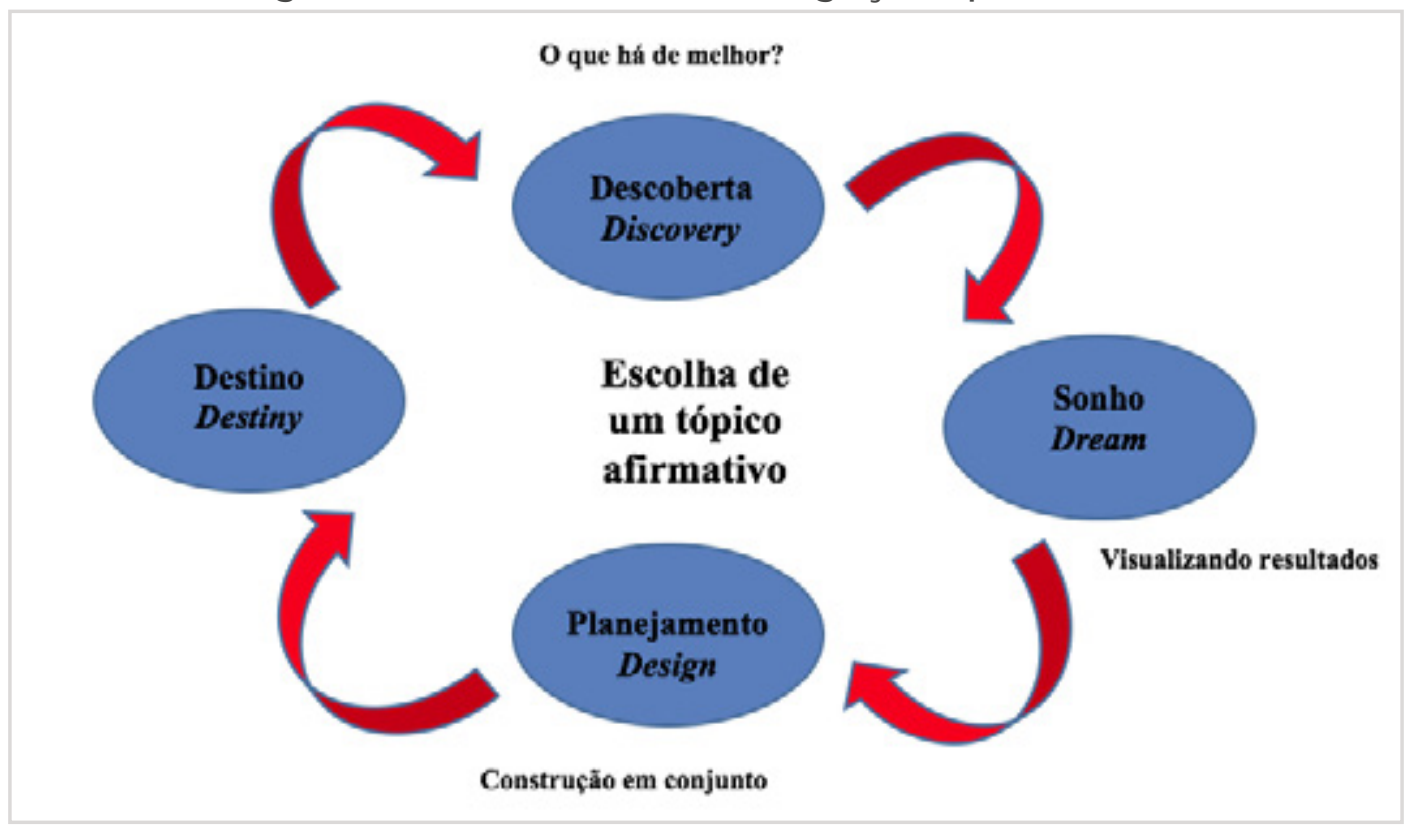

Fonte: Cooperrider; Whitney, 2006, p. 18.

A aplicação do modelo pode se dar de duas formas: a investigação total do sistema e a reunião de cúpula. Na primeira, todos os interessados participam do processo (funcionários, clientes, vendedores, membros da comunidade), tanto na fase da descoberta, quando participam das entrevistas, quanto nas fases posteriores, quando são reunidos para compartilhar histórias e melhores práticas. Já no formato reunião de cúpula, a descoberta do núcleo positivo, delineado com base em dados estratégicos para o negócio, é tarefa da alta gestão. A participação dos demais interessados na cadeia de negócio se dá apenas na elaboração do plano.

\section{Gestão da mudança organizacional}

Diferentemente dos modelos apresentados até aqui, a gestão da mudança organizacional não se apresenta como um modelo de gestão de aplicabilidade direta. Pauta-se muito mais como uma filosofia que permeia a construção de diagnósticos alicerçados em conceitos de inovação e visão para o futuro.

A mudança organizacional só é possível em ambientes abertos e propícios à inovação. Drucker (1998, p. 636), destaca que estratégias empresariais não necessariamente voltadas à inovação focalizam o olhar no futuro, mas prevendo a manutenção de linhas de produtos, serviços, mercados, canais distribuidores e tecnologias atuais. Por outro lado, estratégias empresariais voltadas para a inovação possuem como alicerce o descarte sistemático e planejado do passado, entendendo-se que processos atuais, mesmo que plenamente eficientes, não necessariamente se consolidarão no futuro, mas serão transformados.

Mudanças tecnológicas, de estilo de vida, de leis e regulamentações, demográficas e geopolíticas são alguns exemplos de cenários amplos e essencialmente mutáveis, exigindo das organizações processos de mudança recorrentes. Costa (2007, p. 23) elenca outros tipos de mudanças, consideradas por ele de natureza mais profunda, porém mais sutis. São elas: mudanças na composição da pirâmide etária, mudanças drásticas no posicionamento da opinião pública, mudanças nos papéis sociais e ainda mudanças climáticas, que podem afetar toda uma cadeia produtiva. 
Mesmo diante de cenários tão ciclicamente mutantes, a relutância das organizações no abandono sistemático do passado não é fato incomum, tanto que é altamente recomendável no contexto das iniciativas inovadoras a avaliação de três fatores que determinam a estratégia para a inovação, "a oportunidade final, o risco do insucesso e os esforços e despesas que se façam necessários. Do contrário, as tentativas poderão continuar e mesmo ser intensificadas em uma área em que as oportunidades sejam bastante limitadas, e elevados os riscos do insucesso" (DRUCKER, 1998, p. 639).

A organização inovadora requer um ambiente contínuo de aprendizagem em toda a sua estrutura. É justamente nesse contexto que a gestão da mudança organizacional ganha importância na construção de diagnósticos estratégicos.

Thomaz Wood Jr. (2004, p. 29) aborda o tema de gestão da mudança organizacional como uma resposta "à necessidade ou desejo de as organizações implementarem mudanças planejadas ou alocarem recursos para resolverem questões estratégicas da natureza ambiental, estrutural, de recursos humanos ou tecnológica".

Na visão de Vicente Gonçalves e Carla Campos (2012), a gestão de mudanças pressupõe planejamento, aplicação, medição e monitoramento de gestão do fator humano, compreendendo-se que as pessoas são as maiores responsáveis pelas mudanças organizacionais acontecerem ou não.

Seguindo a lógica de que os indivíduos estão no centro de qualquer processo de mudança, Lucio Gonçalves (2014, p.128) apresenta aspectos essenciais para que a gestão da mudança organizacional seja possível: visão estratégica da mudança, apoio claro dos patrocinadores, conhecimento sobre todos os envolvidos, informações sobre a empresa, identificação de possíveis grupos de poder contra e a favor da mudança, ambiência para mudanças e gestores engajados.

0 autor ressalta ainda a abrangência da gestão da mudança organizacional protagonizada por pessoas, mas que envolve também processos e tecnologia, conforme Quadro 2.

Quadro 2 - Mudança organizacional e perspectivas de gestões

\begin{tabular}{|l|l|l|l|}
\hline \multirow{4}{*}{ GESTÕES } & \multicolumn{1}{|c|}{ PESSOAS } & \multicolumn{1}{c|}{ PROCESSOS } & \multicolumn{1}{c|}{ TECNOLOGIA } \\
\cline { 2 - 4 } & Comunicação & Problemas & Configuração \\
\cline { 2 - 4 } & Conflitos & Processos & Segurança \\
\cline { 2 - 4 } & Conhecimento & Qualidade & \\
\hline & Informação & Riscos & \\
\hline & Resistência & & \\
\hline
\end{tabular}

Fonte: Adaptado de Gonçalves, 2014.

Processos de gestão - muitas vezes pautados por pesquisas de dados primários ou secundários - que visem à intervenção de cenários organizacionais como condição recorrente, permitem que diagnósticos sejam construídos com alicerces estratégicos, em que a situação do presente não seja entendida simplesmente como condição essencial para a projeção da visão de futuro.

\section{O DIAGNÓSTICO EM RELAÇÕES PÚBLICAS}

0 diagnóstico em relações públicas, como um diagnóstico técnico, volta-se a situações que afetam o posicionamento da organização, sua imagem e reputação. Para tanto, deve descrever em termos específicos a comunicação e os relacionamentos 
organizacionais, respondendo às seguintes questões: o que é fonte do problema, onde está a fonte, quando o problema ocorre, quem está envolvido ou é afetado por ele, como esses públicos são envolvidos ou afetados e por que o tema relacionado ao cenário interessa à organização e a seus públicos (CUTLIP, CENTER e BROOM, 1985; BROOM e DOZIER, 1990).

Glen Broom e David Dozier (1990, p. 24) detalham o papel da pesquisa, seja quantitativa ou qualitativa, no processo de formulação do diagnóstico por eles denominado como identificação do problema. Ela se inicia com o monitoramento do ambiente para detecção (percepção de discrepância entre o cenário observado e a situação desejada) e prossegue com 0 detalhamento (sondagens para confirmação da presença de um problema e compreensão da situação) e a descrição do problema (obtenção de informação sistemática e objetiva para definir com precisão a natureza e o alcance do problema).

O monitoramento do ambiente e o detalhamento da situação-problema podem ser conduzidos por meio do levantamento de dados secundários, ou seja, pela coleta de dados pré-existentes. Embora seja uma pesquisa de baixo custo e de rápida execução, já que lança mão de dados públicos e de fácil acesso, requer atenção do profissional à metodologia aplicada em busca de validade e confiabilidade dos dados, bem como à atualidade e à finalidade das informações levantadas para a garantia da relevância e exatidão das informações no contexto em que serão utilizadas.

Ao longo do processo de levantamento de dados, algumas lacunas de informação poderão dificultar a compreensão do cenário, motivo pelo qual a pesquisa de dados primários deve ser usada para obter informações que auxiliem no entendimento amplo e preciso do problema, conforme detalhamento do fluxo na Figura 3.

Figura 3 - Fluxo de pesquisa no processo de planejamento de relações públicas.

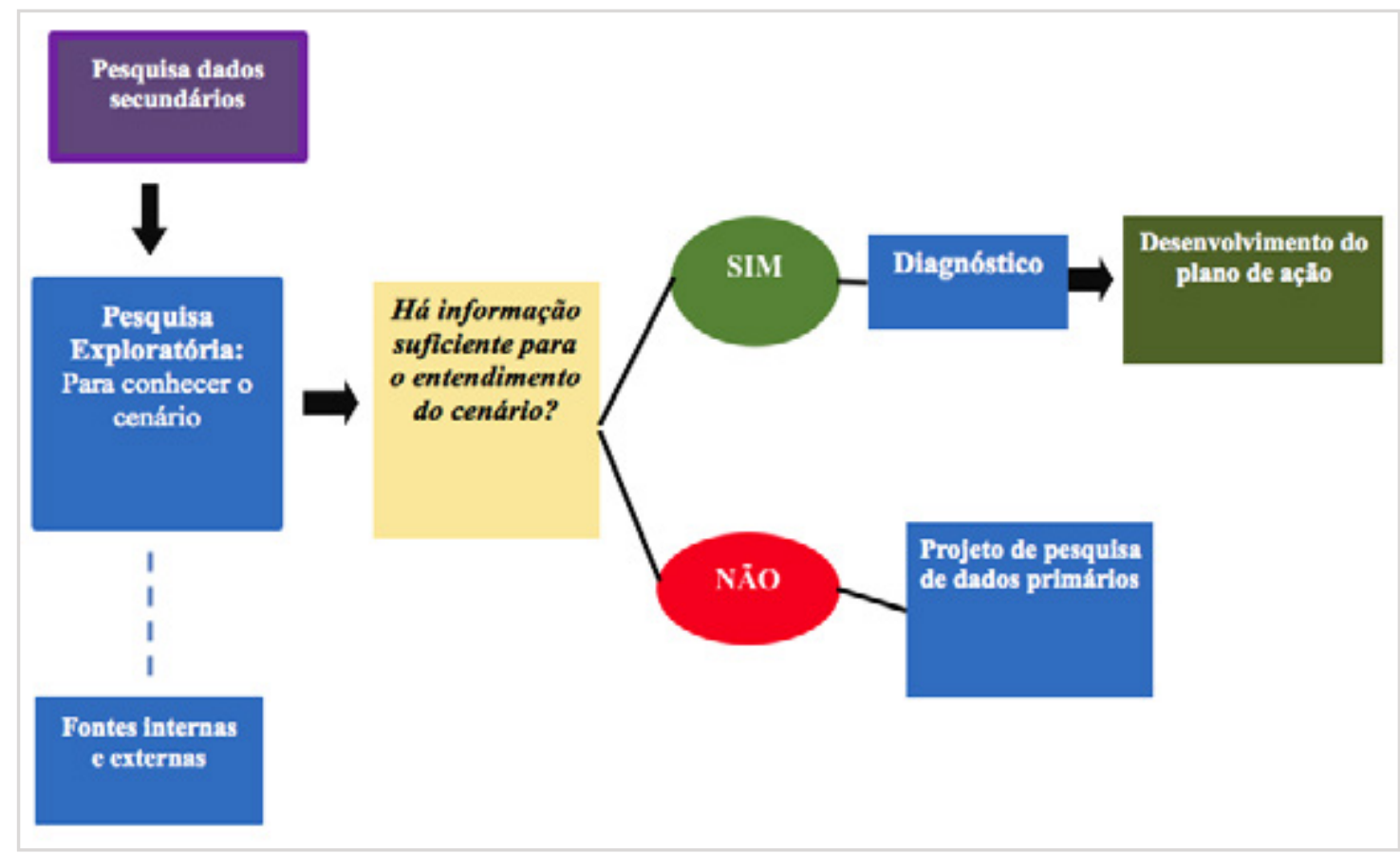

Fonte: Elaborado pelas autoras.

A pesquisa de dados primários será utilizada quando as informações em dados secundários não são suficientes para compreender o cenário organizacional e formular o diagnóstico ou determinar a estratégia de comunicação para subsidiar a elaboração do plano de comunicação.

Não tendo como objetivo do presente artigo o aprofundamento dos diversos tipos de pesquisa direcionados aos estudos de comunicação, mas com o propósito de subsidiar o entendimento acerca das pesquisas de dados primários e secundários, os métodos aplicados em relações públicas e as respectivas técnicas de coleta de dados, o Quadro 3 apresenta panorama conceitual dos usos e aplicações da pesquisa, constituindo-se importante mapa que antecede a construção do diagnóstico. 
Quadro 3 - Usos e aplicações de pesquisa.

\begin{tabular}{|c|c|c|c|c|c|}
\hline $\begin{array}{l}\text { Tipo de } \\
\text { pesquisa }\end{array}$ & $\begin{array}{l}\text { Natureza } \\
\text { do dado }\end{array}$ & $\begin{array}{c}\text { Natureza } \\
\text { da pesquisa }\end{array}$ & $\begin{array}{l}\text { Método de } \\
\text { Pesquisa } \\
\text { em ciências } \\
\text { sociais } \\
\end{array}$ & $\begin{array}{l}\text { Método de } \\
\text { pesquisa } \\
\text { em relações } \\
\text { públicas }\end{array}$ & $\begin{array}{l}\text { Métodos e técnicas de } \\
\text { coleta de dados }\end{array}$ \\
\hline \multirow{4}{*}{ Exploratória } & \multirow{4}{*}{$\begin{array}{l}\text { Dados } \\
\text { secundários }\end{array}$} & & \multirow{4}{*}{$\begin{array}{l}\text { Desk research } \\
\text { ou pesquisa } \\
\text { de gabinete }\end{array}$} & Briefing & $\begin{array}{l}\text { Pesquisa em fontes internas: } \\
\text { - RH: perfil dos funcionários, } \\
\text { investimentos em treinamento, } \\
\text { benefícios, fatores que } \\
\text { podem ocasionar problemas } \\
\text { de relacionamento. } \\
\text { - Marketing e vendas: dados sobre } \\
\text { consumidores, prospects, setor. } \\
\text { - Jurídico: relacionamento } \\
\text { com governo, públicos } \\
\text { afetados pela organização. } \\
\text { - Relatórios de atendimento } \\
\text { (SAC/ ombudsman). } \\
\text { - Análise de conteúdo: relatórios } \\
\text { anuais e demais publicações, } \\
\text { discursos da alta gestão, } \\
\text { campanhas institucionais. }\end{array}$ \\
\hline & & & & $\begin{array}{l}\text { Análise de } \\
\text { macroambiente }\end{array}$ & $\begin{array}{l}\text { Pesquisa em fontes externas: } \\
\text { - Agências e institutos } \\
\text { governamentais. } \\
\text { - Institutos de pesquisa. } \\
\text { - Imprensa especializada. } \\
\end{array}$ \\
\hline & & & & $\begin{array}{l}\text { Análise do } \\
\text { ambiente de } \\
\text { negócio } \\
\text { ou análise setorial }\end{array}$ & $\begin{array}{l}\text { Pesquisa em fontes externas: } \\
\text { - Imprensa: fornece dados sobre } \\
\text { sindicatos, grupos ambientalistas, } \\
\text { de defesa do consumidor. } \\
\text { - Associações profissionais } \\
\text { e de mercado. } \\
\text { - Concorrência: benchmark. }\end{array}$ \\
\hline & & & & $\begin{array}{l}\text { Auditoria de } \\
\text { comunicação: visa } \\
\text { a um estudo focado } \\
\text { nos processos } \\
\text { de comunicação } \\
\text { interna e } \\
\text { administrativa } \\
\text { da organização }\end{array}$ & $\begin{array}{l}\text { Pesquisa em fontes internas: } \\
\text { veículos internos, fluxograma }\end{array}$ \\
\hline
\end{tabular}




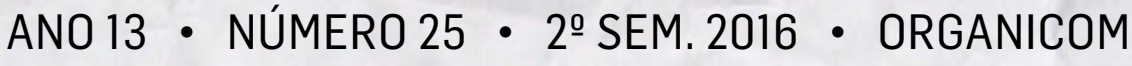

\begin{tabular}{|c|c|c|c|c|c|}
\hline $\begin{array}{l}\text { Tipo de } \\
\text { pesquisa }\end{array}$ & $\begin{array}{l}\text { Natureza } \\
\text { do dado }\end{array}$ & $\begin{array}{c}\text { Natureza } \\
\text { da pesquisa }\end{array}$ & $\begin{array}{l}\text { Método de } \\
\text { Pesquisa } \\
\text { em ciências } \\
\text { sociais }\end{array}$ & $\begin{array}{l}\text { Método de } \\
\text { pesquisa } \\
\text { em relações } \\
\text { públicas }\end{array}$ & $\begin{array}{l}\text { Métodos e técnicas de } \\
\text { coleta de dados }\end{array}$ \\
\hline \multirow{3}{*}{ Exploratória } & \multirow{3}{*}{$\begin{array}{l}\text { Dados } \\
\text { primários }\end{array}$} & \multirow{3}{*}{ Qualitativa } & \multirow{3}{*}{ Pesquisa-ação } & $\begin{array}{l}\text { Auditoria de } \\
\text { opinião: verifica } \\
\text { opinião e reações } \\
\text { dos públicos } \\
\text { formadores de } \\
\text { opinião a respeito } \\
\text { de uma empresa } \\
\text { ou assunto público } \\
\text { de interesse } \\
\text { organizacional. } \\
\text { Auxilia na } \\
\text { identificação } \\
\text { de sub-grupos } \\
\text { favoráveis } \\
\text { ou hostis. }\end{array}$ & $\begin{array}{l}\text { - Grupo de discussão (focus group). } \\
\text { - Entrevista em profundidade. }\end{array}$ \\
\hline & & & & $\begin{array}{l}\text { Auditoria de } \\
\text { imagem: estudo } \\
\text { conduzido com } \\
\text { mais de um público } \\
\text { estratégico para } \\
\text { verificar a imagem } \\
\text { percebida por estes } \\
\text { grupos de interesse } \\
\text { e confrontá-la } \\
\text { com a imagem } \\
\text { pretendida pela } \\
\text { organização. }\end{array}$ & $\begin{array}{l}\text { - Grupo de discussão (focus group). } \\
\text { - Entrevista em profundidade. } \\
\text { - Técnicas projetivas. }\end{array}$ \\
\hline & & & & $\begin{array}{l}\text { Auditoria de } \\
\text { comunicação }\end{array}$ & $\begin{array}{l}\text { - Grupo de discussão (focus group). } \\
\text { - Entrevista em profundidade. } \\
\text { - Observação participante. } \\
\text { - Observação não-participante. }\end{array}$ \\
\hline
\end{tabular}




\begin{tabular}{|c|c|c|c|c|c|}
\hline $\begin{array}{l}\text { Tipo de } \\
\text { pesquisa }\end{array}$ & $\begin{array}{l}\text { Natureza } \\
\text { do dado }\end{array}$ & $\begin{array}{c}\text { Natureza } \\
\text { da pesquisa }\end{array}$ & $\begin{array}{c}\text { Método de } \\
\text { Pesquisa } \\
\text { em ciências } \\
\text { sociais } \\
\end{array}$ & $\begin{array}{c}\text { Método de } \\
\text { pesquisa } \\
\text { em relações } \\
\text { públicas }\end{array}$ & $\begin{array}{l}\text { Métodos e técnicas de } \\
\text { coleta de dados }\end{array}$ \\
\hline \multirow{3}{*}{ Conclusiva } & \multirow{3}{*}{$\begin{array}{l}\text { Dados } \\
\text { primários }\end{array}$} & \multirow{3}{*}{ Quantitativa } & \multirow{3}{*}{ Survey } & $\begin{array}{l}\text { Pesquisa de } \\
\text { opinião: busca } \\
\text { identificar a } \\
\text { opinião de um } \\
\text { público a respeito } \\
\text { de uma questão } \\
\text { de interesse da } \\
\text { organização. }\end{array}$ & $\begin{array}{l}\text { - Questionário estruturado. } \\
\text { - Questionário semi-estruturado. }\end{array}$ \\
\hline & & & & $\begin{array}{l}\text { Pesquisa de } \\
\text { imagem: pesquisa } \\
\text { realizada com } \\
\text { um público } \\
\text { de interesse } \\
\text { para verificar } \\
\text { a percepção } \\
\text { que possui da } \\
\text { organização. }\end{array}$ & • Questionário semi-estruturado. \\
\hline & & & & $\begin{array}{l}\text { Auditoria de } \\
\text { comunicação }\end{array}$ & $\begin{array}{l}\text { - Questionário estruturado. } \\
\text { - Questionário semi-estruturado. }\end{array}$ \\
\hline
\end{tabular}

Fonte: Lopes; Penafieri (2011, p. 290-291).

\section{A CONTRIBUIÇÃO DA PESQUISA EM RELAÇÕES PÚBLICAS NO CONTEXTO DOS MODELOS DE GESTÃO}

Ao buscar a contribuição da pesquisa em relações públicas para a construção de diagnósticos técnicos, a compreensão acerca dos mecanismos oferecidos pela pesquisa no contexto de cada modelo de gestão apresentado neste artigo favorece sua utilização de modo mais assertivo, levando-se em conta a natureza do dado, a natureza da pesquisa e o método utilizado, de acordo com o exposto no Quadro 4. 
Quadro 4 - Modelos de gestão e possibilidades de pesquisa.

\begin{tabular}{|c|c|c|c|}
\hline $\begin{array}{c}\text { Modelos de gestão } \\
\text { versus } \\
\text { possibilidades } \\
\text { de pesquisa }\end{array}$ & $\begin{array}{c}\text { Natureza dos dados } \\
\text { da pesquisa }\end{array}$ & Natureza da pesquisa & $\begin{array}{l}\text { Método de pesquisa } \\
\text { em relações públicas }\end{array}$ \\
\hline $\begin{array}{l}\text { PDCA } \\
\text { Planejamento } \\
\text { Execução } \\
\text { Avaliação } \\
\text { Correção }\end{array}$ & $\begin{array}{l}\text { Dados secundários } \\
\text { e primários }\end{array}$ & Quantitativa & $\begin{array}{l}\text { Pesquisa de opinião } \\
\text { Pesquisa de imagem }\end{array}$ \\
\hline $\begin{array}{l}\text { BSC } \\
\text { Finanças } \\
\text { Processos/negócios } \\
\text { Clientes } \\
\text { Aprendizado/crescimento }\end{array}$ & $\begin{array}{l}\text { Dados primários } \\
\text { e secundários }\end{array}$ & $\begin{array}{l}\text { Pesquisa qualitativa } \\
\text { e quantitativa }\end{array}$ & $\begin{array}{l}\text { Pesquisa de opinião } \\
\text { Pesquisa de imagem } \\
\text { Auditoria de comunicação }\end{array}$ \\
\hline $\begin{array}{l}\text { IA } \\
\text { Descoberta } \\
\text { Sonho } \\
\text { Destino } \\
\text { Descoberta }\end{array}$ & $\begin{array}{l}\text { Dados primários } \\
\text { e secundários }\end{array}$ & Pesquisa qualitativa & Auditoria de opinião \\
\hline $\begin{array}{l}\text { GMO } \\
\text { Planejamento } \\
\text { Aplicação } \\
\text { Medição } \\
\text { Monitoramento } \\
\text { (do fator humano) }\end{array}$ & $\begin{array}{l}\text { Dados primários } \\
\text { e secundários }\end{array}$ & $\begin{array}{l}\text { Pesquisa qualitativa } \\
\text { e quantitativa }\end{array}$ & $\begin{array}{l}\text { Pesquisa de opinião } \\
\text { Auditoria de comunicação }\end{array}$ \\
\hline
\end{tabular}

Fonte: Elaborado pelas autoras.

No ciclo PDCA a pesquisa contribui tanto para a elaboração do diagnóstico, em busca da identificação das falhas de comunicação que impactam o desempenho organizacional e de outras áreas, quanto na avaliação do processo comunicacional e mensuração dos resultados por ele obtidos.

No modelo BSC a pesquisa contribui para todas as perspectivas: em finanças na identificação da percepção de acionistas e investidores acerca da organização; em processos internos, na avaliação dos processos essenciais à satisfação dos clientes; na perspectiva clientes, no monitoramento da relação com esse stakeholdervisando à sua manutenção; em aprendizado e crescimento, no mapeamento de processos a ser aprimorados, habilidades e competências a serem desenvolvidas.

No contexto da investigação apreciativa (IA), a pesquisa é adotada especialmente no modelo de aplicação denominado investigação total do sistema, no qual diferentes stakeholders podem ser envolvidos na construção do núcleo positivo, 
momento da descoberta, necessário à construção do sonho. 0 método qualitativo é empregado em busca do detalhamento dos pontos fortes e das melhores práticas organizacionais, e a coleta de dados pode ser realizada por meio de grupos de discussão. No formato reunião de cúpula, o núcleo positivo é construído pela alta gestão a partir de dados secundários sobre a estratégia organizacional ou mesmo dados primários a respeito do contexto e seu impacto sobre a organização.

No modelo de gestão de mudança organizacional a pesquisa contribui em todos os processos de modo contínuo. Para que a filosofia constante de inovação e a mudança projetada sejam possíveis, informações de micro e macroambiente necessitam de mapeamento constante. Para que a gestão da mudança seja um modelo viável, o fator humano deve ser priorizado, fazendo com que os públicos envolvidos no processo de gestão sejam ouvidos, monitorados e incentivados a participar em todas as frentes de mudança.

\section{CONSIDERAÇÕES FINAIS}

É notório que os modelos de gestão apresentados não esgotam as possibilidades de contribuição estratégica para elaboração de diagnósticos, mas colaboram fortemente para a compreensão dos inúmeros cenários e variáveis que submergem em um contexto analítico e que são potencializados com informações de natureza primária ou secundária possibilitadas pela pesquisa.

Compreender a pesquisa em comunicação como parte de um processo estratégico organizacional é condição essencial para quaisquer ações que redundem em tomada de decisões. 0 artigo atingiu o objetivo de abordar panoramicamente a pesquisa em comunicação e seus conceitos e inseri-la como ferramenta preliminar e imprescindível para a elaboração de diagnósticos estratégicos, tema aprofundado a partir de modelos de gestão que atuam como caminhos diretivos para que 0 diagnóstico alcance seu principal propósito: analisar a relevância de aspectos do presente e projetar cenários futuros.

\section{REFERÊNCIAS}

ARAÚJO, Luis C. G. Organização, sistemas e métodos e as tecnologias de gestão organizacional. 2. ed. São Paulo: Atlas, 2009.

BROOM, Glen M.; DOZIER, David M. Using research in PR: applications to program management. New Jersey: Prentice Hall, 1990.

CUTLIP, Scott M.; CENTER, Allen H.; BROOM, Glem M. Effective public relations. 6th ed. New Jersey: Prentice Hall, 1985.

COOPERRIDER, David L. E WHITNEY. Investigação apreciativa: uma abordagem positiva para gestão de mudanças. Rio de janeiro: Qualtimark, 2006.

COSTA, Ana Paula Paulino. BSC: conceitos e guia de implementação. São Paulo: Atlas, 2006.

COSTA, Eliezer A. Gestão estratégica: da empresa que temos para a empresa que queremos. 2. ed. São Paulo: Saraiva, 2007.

DRUCKER, Peter F. Introdução à administração. Trad. de Carlos A. Malferrari. 3. ed. São Paulo: Pioneira, 1998.

GONÇALVES, Lucio L. Gestão de mudanças na teoria e na prática e o método das gestões. São Paulo: All Print Editora, 2014. 
GONÇALVES, Vicente; CAMPOS, Carla. Gestão de mudanças: o fator humano na liderança de projetos. Rio de Janeiro: Brasport, 2012.

KAPLAN, Robert; NORTON, David. Balanced scorecard: a estratégia em ação. 15. ed. Rio de Janeiro: Campus, 2003.

LIKER, Jefrey; MEIER, David. O modelo Toyota. Porto Alegre: Bookman, 2007.

LOPES, Valéria S. de Castro; PENAFIERI, Vânia. Opinião e pesquisa: instrumentos de orientação e de avaliação. In: FARIAS, Luiz Alberto (Org.). Relações públicas estratégicas: técnicas, conceitos e instrumentos. São Paulo: Summus, 2011.

TAVARES, Mauro Calixta. Gestão estratégica. São Paulo: Atlas, 2000.

WOOD JR., Thomaz (Coord.). Mudança organizacional. 4. ed. São Paulo: Atlas, 2004.

Artigo recebido em 25.10.2016 e aprovado em 16.11.2016. 